American Journal of Applied Sciences 8 (9): 897-902, 2011

ISSN 1546-9239

(C) 2011 Science Publications

\title{
Computer Modeling of a CI Engine for Optimization of Operating Parameters Such as Compression Ratio, Injection Timing and Injection Pressure for Better Performance and Emission Using Diesel-Diesel Biodiesel Blends
}

\author{
${ }^{1} \mathrm{M}$. Venkatraman and ${ }^{2} \mathrm{G}$. Devaradjane \\ ${ }^{1}$ Department of Mechanical Engineering, Arulmigu Meenakshi Amman \\ College of Engineering, Kanchipuram-604 410, TamilNadu, India \\ ${ }^{2}$ Department of Automobile Engineering, Anna University, MIT Campus, \\ Chrompet, Chennai-600 044, TamilNadu, India
}

\begin{abstract}
Problem statement: The present work describes a theoretical investigation concerning the performance of a four strokes compression ignition engine, which is powered by alternative fuels in the form of diesel and diesel biodiesel blends. Approach: The developed simulation model used to estimate the cylinder pressure, heat release rate, brake thermal efficiency, brake specific fuel consumption and engine out emissions. The simulation model includes Honerberg's equation heat transfer model, Zero dimensional combustion model for the prediction of combustion parameters. Results: Experiments were performed in a single cylinder DI diesel engine fuelled with a blend of pungam methyl ester for the proportion of PME10, PME20 and PME30 by volume with diesel fuel for validation of simulated results. Conclusion/Recommendations: It was observed that there is a good agreement between simulated and experimental results which reveals the fact that the simulation model developed predicts the performance and emission characteristics of any biodiesel and diesel fuel and engine specifications given as input.
\end{abstract}

Key words: CI engine, combustion parameters, emission characteristics, dimensional combustion, zone model, Actual Cycle Simulation (ACS), ignition engine, Standard Deviation (SD), ignition delay, Carbon Monoxide (CO)

\section{INTRODUCTION}

There is intense research efforts are being carried out to identify the potential biodiesel to develop less polluting and more efficient engines. The numerical simulation was preferred to study the combustion behavior and emission of diesel engine because the experimental investigations were time consuming and costly affair. A computer based mathematical model have been proposed in the present work to study and understand the combustion and performance. The various models proposed are one zone and multi zone models. In the present work the analysis of progressive combustion using zero-dimensional single-zone model is used and assumed the entire combustion chamber is considered as single zone. In the final step using simplified assumptions, the engine heat transfer can be taken into account by means of empirical equations. Gas exchange processes are introduced in order to analyze the engine intake and exhaust. This analysis is called Actual Cycle Simulation (ACS). In this analysis the intake and exhaust processes using fluid dynamic equations, heat transfesr and friction are included by means of empirical equations. By means of this step-by-step simulation, the values of pressure, volume and temperature at salient points in the cycle are calculated. Work output as well as thermal efficiency is evaluated. Many researchers have investigated the effects of oxygenated compounds on performance and emissions in a diesel engine Komintarachat and Chuepeng (2010) The produced biodiesel may be used in diesel engines if other properties are tested for compatibility. This provides one more choice for alternative energy and commercialization.

Ganesan (1996) is the first who introduces the computer simulation is the process of formulating a model of a physical system representing actual processes and analyzing the same. Usually, the model is a mathematical one representing the actual processes

Corresponding Author: M. Venkatraman, Department of Mechanical Engineering, Arulmigu Meenakshi Amman College of Engineering, Kanchipuram, 604 410, Tamilnadu, India 
through a set of algebraic, differential or integral equations and the analysis is made using a computer. It considerable reduces the time-consuming tests by narrowing down the variables that must be studied. It helps in optimizing the engine design for a particular application, thereby reducing cost and time.

Momani et al. (2009). This technique can be used partially; in some conditions oxygen can be feed into the combustion chambers to increase engine performance. It's recommended to use another fuel additives or mixtures to study its effects on air-fuel ratios. Heywood (1998) is the first person who introduces computers to simulate the flow through engine gas exchange system. Kumanan and Raja (2008) A Petri net aided software, a PETRI-PM is developed to model, simulate and analyze the project.

Heywood (1998) and Benson and Whitehouse (1979) analyzed Heat release rate based on first law of thermodynamics and state equation. He proposed to use more sophisticated models for the gas properties before, during and after combustion with accurate heat transfer model. Many researchers have investigated the effects of biodiesel on performance and emissions in a diesel engine Jung and Assanis (2001) used a quasi steady gas exchange model combined with a two zone combustion model to calculate performance and emission and optimize the engine operating parameters. Rao and Ganesan (2010) the investigation has been carried out using the software STAR-CD. The effect of piston bowl shapes (bath tub, shallow and flat), compression ratios (11.2, 12 and 12.5), different intake port geometries (helical, tangential and straight) and engine speeds (1500, 2000, 2500 and $3000 \mathrm{rpm})$ on the turbulence kinetic energy and swirl ratio has been studied. From the analysis of the flow field, shallow bowl seems to be preferable from the point of swirl ratio at lower compression ratio, but at higher compression ratio flat bowl shape is preferable (Kaliravna et al., 2010). Through statistical tools it is easy to interpret that what were the values of certain parameters when customers rated that particular engine as good, average or bad. Some of these tools used here are Standard Deviation (SD), Coefficient Of Variance (COV) and Lowest Normalized Value (LVN). The Standard Deviation (SD) and Lowest Normalized Value (LNV) of Indicative Mean Effective Pressure (IMEP) are determined through the analysis of in-cylinder pressure data of the engine. It has been observed that with second camshaft value of SD and LNV of IMEP is improved significantly which in turn shows improved combustion stability at idling in both fuel modes, Najafi et al. (2007) An Artificial Neural Network (ANN) was developed based on the collected data of this work.
Multi Layer Perceptron network (MLP) was used for nonlinear mapping between the input and the output parameters.

Kannan and Udayakumar (2009) based on the model description a computer program is developed using $\mathrm{C}$ program for the diesel cycle simulation to predict the cylinder pressure for the complete cycle and performance parameters can be effectively evaluated. A CFD studies on combustion and emission of diesel engine using Fluent is required to evaluate the emission data. The present work aims to develop a single zone zero dimensional model for DI diesel engines running with biodiesel to predict the engine performance and emission parameters. An experimental work is also conducted in a 4-stroke single cylinder compression ignition engine for comparison with simulated results. It is revealed from the results that the simulation model developed for biodiesel is in very good agreement with experimental results.

\section{MATERIALS AND METHODS}

Mathematical treatment: Conservation and state equations: This model is based on the first law of thermodynamics is applied. For a closed system, the first law of thermodynamics states that:

$$
\mathrm{dQ}-\mathrm{dW}=\mathrm{dE}
$$

Where dQ is the heat loss to the chamber walls, $\mathrm{dW}$ is the network energy and $\mathrm{dE}$ is the change in internal energy.The pressure at each crank angle can be calculated using the relation:

$$
\mathrm{pV}=\mathrm{M} \mathrm{R}_{\mathrm{mol}} \mathrm{T}
$$

Where:

$\mathrm{M}=$ The number of $\mathrm{kg}$-mols

$\mathrm{V}=$ The Cylinder volume

The volume at each crank angle $\mathrm{V}_{\text {ca }}$ is calculated using the relation:

$$
\begin{gathered}
\mathrm{V}(\mathrm{THETA})=\mathrm{vdisp} *[\mathrm{cr} /(\mathrm{cr}-1)-(1-\cos \Theta) / 2+1 / \mathrm{s}-1 / 2 * \sqrt{ } \\
{\left[(2 \mathrm{l} / \mathrm{s})^{\wedge} 2-\sin ^{2} \Theta\right]}
\end{gathered}
$$

Fuel injection rate: The fuel injection rate is calculated using the relation:

$$
\mathrm{m}_{\mathrm{fi}}=\mathrm{C}_{\mathrm{d}}(\pi / 4) \mathrm{d}_{\mathrm{n}}^{2}\left(2 \Delta \mathrm{P}_{\mathrm{n}} / \rho_{\mathrm{f}}\right)^{0.5}
$$

where, $\Delta \mathrm{P}_{\mathrm{n}}$ is the pressure difference across the injector hole. 
Am. J. Applied Sci., 8 (9): 897-902, 2011

Heat transfer process: Heat transfer coefficient: The heat transfer coefficient between cylinder gases and wall is calculated by Hohenberg's correlation given as:

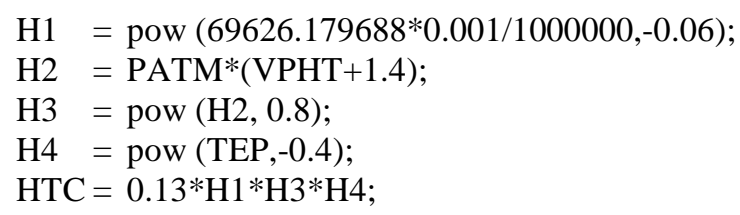

Combustion duration: The duration of combustion varies according to the empirical expression given by:

$$
\begin{gathered}
\text { Combustionduration }=40+5 *(\mathrm{RPM} / 600-1) \\
+166 *(\mathrm{ycc} / \mathrm{y}-1.1)^{2}
\end{gathered}
$$

Combustion model: Heat release rate is calculated using wiebe heat release model(zero dimensional combustion model) is based on the exponential rate of the chemical reactions.In this model,it is assumed that all the fuel is injected is injected before the end of ignition delay period itself:

$$
\begin{gathered}
\mathrm{ROHR}(\mathrm{dQc} / \mathrm{d} \Theta)=\mathrm{a}^{*}(\mathrm{~m}+1) *(\mathrm{Qav} / \mathrm{COMBDUR}) \\
{ }^{\wedge} \mathrm{m} *[(\Theta-\text { SOC }) / \mathrm{COMBDUR}]^{\wedge} \mathrm{m} * \exp \left[-\mathrm{a}^{*}(\Theta-\right. \\
\text { SOC } \left.) / \text { COMBDUR }]^{\wedge}(\mathrm{m}+1)\right]
\end{gathered}
$$

Where:

$$
\begin{aligned}
\mathrm{A} & =6.908 \\
\mathrm{M} & =2 \\
\mathrm{Q} a \mathrm{v} & =\mathrm{QP} 2
\end{aligned}
$$

$$
\begin{gathered}
\text { (Energy Release at Constant Pressure) } \\
\text { QP2 }=(\text { hrp } 1+\mathrm{N} 1 * 282800) * \text { sf2 }
\end{gathered}
$$

Ignition delay: Ignition delay time can be calculated as the difference between the time at which combustion starts and the time at which injection starts. Ignition delay is a complicated function of mixture temperature, pressure and equivalence ratio and fuel properties. The correlation proposed by wolfer's relation is used in the model:

$$
\text { Ignition delay }=[0.44 * \exp (4650 / \mathrm{AT} 2)] /(\mathrm{AP} 2 \wedge 1.19)
$$

$\mathbf{N O}_{\mathbf{x}}$ formation: To calculate the formation of nitric oxide inside each zone, a chemical equilibrium scheme is used to calculate the concentration of various components under equilibrium conditions.In the present work extended zeldovich mechanism is used for calculation of NO formation. NOx formation is strong dependant on temperature and oxygen concentration:

$$
\mathrm{d}(\mathrm{NO}) / \mathrm{dt}=6^{*} 10^{6} / \mathrm{T}^{0.5} \exp (-69090 / \mathrm{T})\left[\mathrm{O}_{2}\right]_{\mathrm{e}}^{0.5}\left[\mathrm{~N}_{2}\right]_{\mathrm{e}}
$$

The equilibrium oxygen and nitrogen concentration in the burned zone are given by:

$$
\left[\mathrm{O}_{2}\right]_{\mathrm{e}}=\mathrm{f}_{\mathrm{O} 2}(\mathrm{P}, \mathrm{T})\left[\mathrm{N}_{2}\right]_{\mathrm{e}}=\mathrm{f}_{\mathrm{N} 2}(\mathrm{P}, \mathrm{T})
$$

Experimental description: Specification is given in Table 1. A Electrical dynamometer was used to apply the load on the engine. A water rheostat with an adjustable depth of immersion electrode was provided to dissipate the power generated.Tests were carried out at various loads starting from no load to full load condition at a constant rated speed of $1500 \mathrm{rpm}$. At each load, the fuel flow rate various constituents of exhaust gases such as Hydrocarbon (HC), Carbon Monoxide (CO) and Nitrogen Oxides $\left(\mathrm{NO}_{\mathrm{x}}\right)$, were measured with a 5 gas MRU Delta exhaust gas analyzer. The analyzer uses the principle of NonDispersive Infrared(NDIR) for the measurement of CO and $\mathrm{HC}$ emissions while $\mathrm{NO}_{\mathrm{x}}$ measurement was by means of electrochemical sensors.Combustion analysis was carried out by means of an AVL pressure pick-up fitted on the cylinder head and a TDC encoder fixed on the output shaft of the engine. The pressure and the crank angle signals were fed to pentium personal computer. Various combustion parameters like heat release rate, cumulative heat release rate and peak pressure and its accurance were obtained using data acquisition system.The properties of the fuel at various volumetric proportions as specified in Table.2.The engine was first operated with diesel oil to generate the baseline data followed by pungam methyl esters and their blends such as PME10, PME20 and PME30 blends.

\section{Notation:}

BTHE: brake thermal efficiency

BSFC: brake specific fuel consumption

HRR: heat release rate

PME: $\quad$ pungam methyl ester

PME10: blend of biodiesel and diesel having 10\% biodiesel and remaining diesel

PME20: blend of biodiesel and diesel having 20\% biodiesel and remaining diesel

PME30: blend of biodiesel and diesel having 30\% biodiesel and remaining diesel

Tables and its titles must be centered. Number tables consecutively in order of appearance and place them as close as possible to where they are first referenced in the text. Place table titles above the tables. Refer to tables as Table 1 or Table 1-2, in the body of text. Leave one line space of $11 \mathrm{pt}$ before and after the table. 
Am. J. Applied Sci., 8 (9): 897-902, 2011

Table 1: Engine specifications

\begin{tabular}{ll}
\hline Make & Kirloskar \\
\hline Model & TAF 1 \\
Type & Direct injection, air cooled \\
Bore $\times$ stroke $(\mathrm{mm})$ & $87.5 \times 110$ \\
Compression ratio & $17.5: 1$ \\
Cubic capacity & $0.661 \mathrm{lit}$ \\
Rated power & $4.4 \mathrm{KW}$ \\
Rated speed & $1500 \mathrm{rpm}$ \\
Start of injection & $24^{\circ} \mathrm{bTDC}$ \\
Connecting rod length & $220 \mathrm{~mm}$ \\
Injector operating pressure & $220 \mathrm{bar}$ \\
\hline
\end{tabular}

Table 2: Properties of the different fuel blends

\begin{tabular}{|c|c|c|c|}
\hline Details & Diesel & Raw pongamia & PME \\
\hline Density $\mathrm{kg} \mathrm{m}^{-3}$ & 821.00 & 934.00 & 892.000 \\
\hline CV kj/ kg & 43000.00 & 35648.00 & 39149.000 \\
\hline Flashpoint ${ }^{\circ} \mathrm{C}$ & 48.00 & 270.00 & 156.000 \\
\hline KV cst & 3.52 & 45.62 & 5.405 \\
\hline $\mathrm{CN}$ & $48-56$ & 47.00 & 57.000 \\
\hline
\end{tabular}

\section{RESULTS AND DISCUSSION}

The simulation model is capable of predicting various performance, combustion and emission parameters based on the any engine and any fuel specifications given as input .The developed simulation model can be useful for both diesel and any biodiesel blends. It serves as a versatile tool for a better understanding of the variables involved and their effect on engine performance and also it helps in optimizing the engine design for a particular application, thereby reducing cost and time. Experimental investigation were carried out at different compression ratio, injection timing and injection pressure and its details are mentioned in Table 3. At injector opening pressure of 200bar and 220bar and injection timing of $21^{\circ} \mathrm{bTDC}$ and $24^{\circ} \mathrm{bTDC}$ and compression ratio of 17.5:1 and 16:1 were tried for PME10,PME20 and PME30 but from the investigation it was found that the performance was very poor. Further the engine were set to run at higher compression ratio of 19:1, advanced injection timing of $27^{\circ} \mathrm{bTDC}$ and higher injector opening pressure of 240 bar it arrives at the optimum range operating parameters for PME20. It was observed that PME20 it gives better performance for the optimized operating parameters. Finally the theoretical results of cylinder pressure, brake power, thermal efficiency, Specific fuel consumption and harmful pollutants such as nitric oxide, carbon monoxide and hydrocarbon are validated with experimental results. The predicted results of performance and emissions have been in close agreement with experimental results. The developed simulation model appears to be a useful tool for analyzing the diesel engine combustion accurately.
Table 3: Operating parameters considered in the present investigations

\begin{tabular}{ll}
\hline Load (\%) & $0,25,50,75,100$ \\
\hline Speed (rev/min) & 1500 \\
Compression ratio & $16: 1,17.5: 1,19: 1$ \\
Injection Timing ${ }^{\circ}$ bTDC & $21,24,27$ \\
Injection pressure (bar) & $200,220,240$ \\
\hline
\end{tabular}

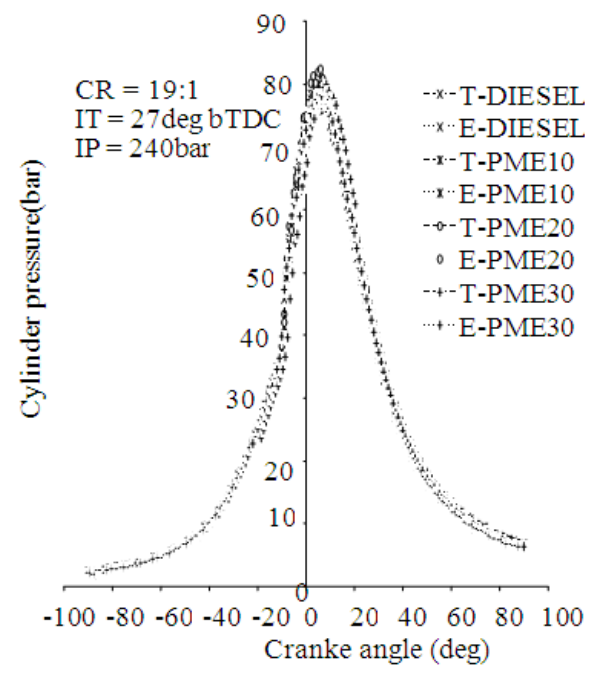

Fig. 1:Comparison of experimental and predicted cylinder pressure for three different biodiesel blends with respect to crank angle

Figure1 shows that the comparison of experimental and predicted cylinder pressure for three different biodiesel blends and diesel fuel with respect to crank angle for various engine operating conditions. The agreement between the predicted values and experimental values of cylinder pressure are satisfactory.

Figure 2 shows the comparison of experimental and predicted heat release rates for diesel and biodiesel blends. From the results it was observed that the heat release rate increases during premixed combustion and decreases during diffusion combustion. The increase in heat release rate is due to the decrease in delay period. As revealed by the figure the combustion model predicts very well the heat release rates in the engine cylinder.

Figure 3 shows the comparison of experimental and predicted brake thermal efficiency for three different biodiesel blends with respect to brake power. The predicted values of brake thermal efficiency for all biodiesel blends are similar experimental brake thermal efficiency.

Figure 4 shows the brake specific fuel consumption predicted by the simulation model and the experimental one. It is seen that the fuel consumption of biodiesel blends is lower than that of diesel fuel operation which is due to better combustion in the cylinder. 
Am. J. Applied Sci., 8 (9): 897-902, 2011

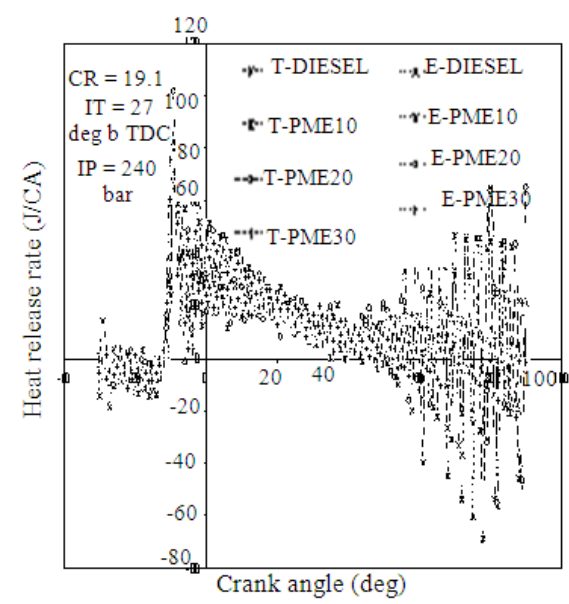

Fig. 2: Comparison of experimental and predicted heat release rate for three different biodiese blend with respect to crank angle

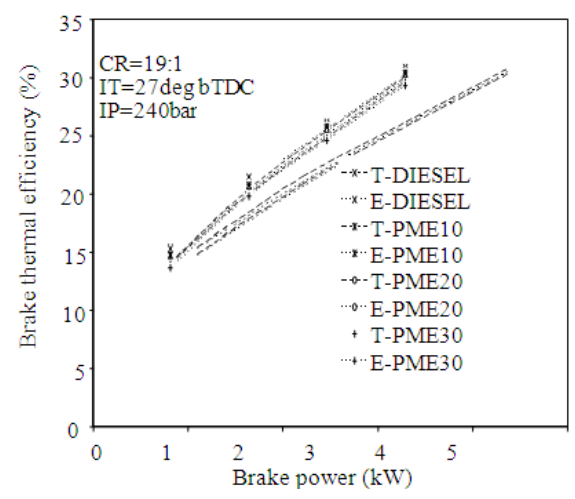

Fig. 3: Comparison of experimental and predicted brake thermal efficiency for three different biodiesel blends with respect to brake power

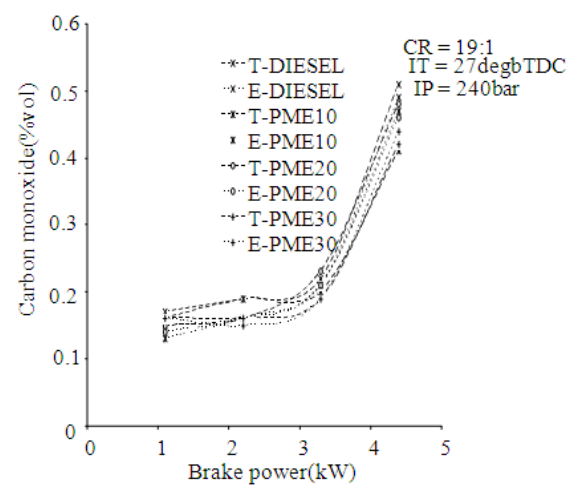

Fig. 4:Comparison of experimental and predicted carbon monoxide for three different biodiesel blends with respect to brake power

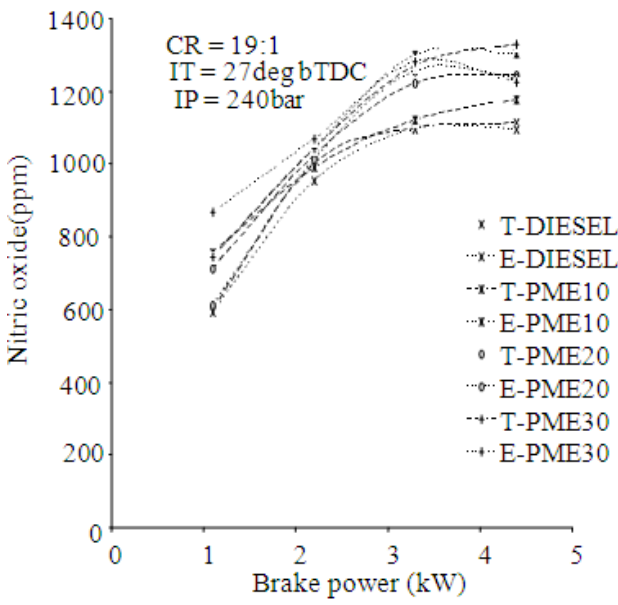

Fig. 5: Comparison of experimental and predicted nitric oxide for three different biodiesel blends with respec to brake power

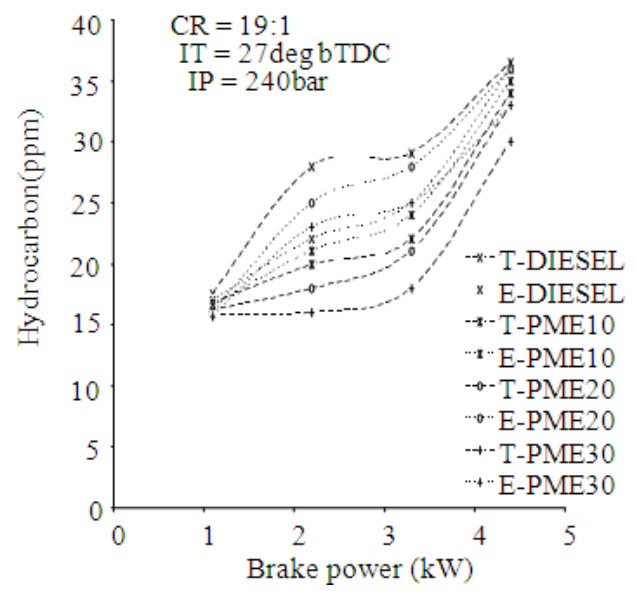

Fig. 6: Comparison of experimental and predicted hydrocarbon for three different biodiesel with respect to brake power

Due to the better consumption of the fuel BSFC have moderate improvement. The coincidence between the predicted and measured values is good.

Figure 5 shows the calculated and measured $\mathrm{CO}$ (in $\%$ vol) with respect to the loads. $\mathrm{CO}$ emissions are greatly dependant on the air fuel ratio relative to stoichiometric proportions. It is seen from the figure that the full load emission of $\mathrm{CO}$ for diesel is $0.49 \%$ and that of biodiesel blend with diesel is $0.2 \%$ predicted by the simulation model. The experimental values are $0.51 \%$ for diesel and $0.48 \%$ for DGM blends with diesel at full load. Due to better combustion of biodiesel blends with diesel, CO emissions present in the exhaust are reduced. 
Figure 6 shows the comparison of $\mathrm{HC}$ with respect to the load predicted by the simulation model and the experimental one. Biodiesel blend addition decreases the $\mathrm{HC}$ values with respect to increase of load as shown. Hydrocarbon emission is decreased by about $3 \%$ predicted by the simulation model. Diesel fuel contains chain and substituted types of aromatic compounds, burns more slowly and produces higher amounts of unburnt hydrocarbons. The $\mathrm{HC}$ emissions of biodiesel blends is reduced due to better combustion of the fuel.

\section{CONCLUSION}

In the present work a single zone zero dimensional model for direct injection diesel engine has been developed to predict the performance characteristics.

The predicted results of performance and emissions have been in close agreement with experimental results. The developed simulation model appears to be a useful tool for analyzing the diesel engine combustion accurately. Thus the developed computer model can predict the various performance and emission parameters of any vegetable oil esters with minimum inputs such as density, calorific value, chemical formula and engine specification.

Moreover the developed model can be considered as an efficient tool to calculate the effect of engine operating parameters such as compression ratio, injection timing and injection pressure. Finally it is concluded that the predictions revealed fair agreement with experimental results. Hence the developed simulation C-programming model is validated of any given vegetable oil esters at various operating parameters of diesel engine.

\section{ACKNOWLEDGEMENT}

We thank the management of Sri Venkateswara College of Engineering Sriperumbudur, chennaiTamilnadu-India for providing us with the necessary experimental set up to perform this experimental research for validate the simulation results.

\section{REFERENCES}

Benson, R.S. and N.D. Whitehouse, 1979. Internal Combustion Engines: A Detailed Introduction to the Thermodynamics of Spark and Compression Ignition Engines, their Design and Development. 1st Edn., Pergamon Press, England, ISBN: 0080227201, pp: 430.
Ganesan, V., 1996. Computer Simulation of SparkIgnition Engine Processes. 1st Edn., Universities Press, Hyderabad, India, ISBN-10: 8173710155, pp: 231.

Heywood, J.B., 1998. Internal Combustion Engine Fundamentals. 1st Edn., McGraw Hill, New York, ISBN: 007028637X, pp: 930.

Jung, D. and D.N. Assanis, 2001. Multi zone DI Diesel spray combustion model for cycle simulation studies of engine performance and emissions. Society of Automotive Engineers, Inc.

Kaliravna, J.S., M. Nimbalkar, N.K. Jain and V. Ganesan, 2010. Combustion quality measurements at idling in a bi-fuel engine using statistical tools. Int. J. Green Energy, Energy Enviorn.

Kannan, K. and M. Udayakumar, 2009. Modeling of nitric oxide formation in single cylinder direct injection diesel engine using diesel-water emulsion. Am. J. Applied Sci., 6: 1313-1320. DOI:10.3844/ajassp.2009.1313.1320

Komintarachat, C. and S. Chuepeng, 2010. Methanolbased transesterification optimization of waste used cooking oil over potassium hydroxide catalyst. Am. J. Applied Sci., 7: 1073-1078 DOI: 10.3844/ajassp.2010.1073.1078

Kumanan, S. and K. Raja, 2008. Modeling and simulation of projects with petri nets. Am. J. Applied Sci., 5: 1742-1749. DOI:10.3844/ajassp.2008.1742.1749

Momani, W., S. Abu-Ein, M. Momani and S.M. Fayyad, 2009. Effects of oxygenated gasoline on fuel and air mass flow rates and air-fuel ratio. Am. J. Applied Sci., 6: 974-977. DOI: 10.3844/ajassp.2009.974.977

Najafi, G., B. Ghobadian, T.F. Yusaf and H. Rahimi, 2007. Combustion analysis of a CI engine performance using waste cooking biodiesel fuel with an artificial neural network aid. Am. J. Applied Sci., 4: 759-767. DOI: 10.3844/ajassp.2007.759.767

Rao, B.S.N. and V. Ganesan, 2010. CFD analysis of combustion chamber geometry for the possibility of hydrogen fueling in a spark-ignition engine. Int. J. Green Energy, Energy Enviorn. 